\title{
Desafios para a maternidade no contexto da reprodução medicamente assistida: terceiro mês do bebê $\hat{e}^{1}$
}

\author{
Lia Mara Netto Dornelles \\ Rita de Cássia Sobreira Lopes \\ Universidade Federal do Rio Grande do Sul
}

\begin{abstract}
Resumo
O desgaste físico e emocional decorrente das técnicas de reprodução medicamente assistida, pode conferir à maternidade um caráter específico, com repercussões ainda pouco conhecidas. Por meio deste estudo com três mulheres que engravidaram por técnicas reprodutivas, buscou-se conhecer o processo de tornarse mãe no contexto da reprodução medicamente assistida, com medidas coletadas aos três meses do bebê. Os resultados apontaram que a transição para a maternidade foi vivida por essas mulheres com sentimento de incapacidade de cuidar adequadamente de seu bebê e medo de que ele não sobrevivesse, sendo que o nascimento pré-termo, já temido desde a gestação, tornou real a possibilidade de perda do bebê e a vivência dessa etapa, um desafio. Entretanto, observou-se que superado esse período inicial, o medo da perda do bebê diminuiu, dando espaço para o estabelecimento da crença de que essas mães são capazes de garantir a sobrevivência de seus bebês.
\end{abstract}

Palavras-chave: maternidade; reprodução medicamente assistida; infertilidade.

\begin{abstract}
Challenges to motherhood in the context of assisted reproduction: infant's third month of life.

The physical and psychological stress produced by the assisted reproduction techniques (ART) may affect parenthood in a special way, with unknown repercussions. This study aims at knowing the process of becoming a mother in three women who conceived through ART and whose babies were three months old. The results showed that the participants of this study went through the transition to parenthood feeling uncapable of taking care of their babies in an appropriate way and also frightened by the possibility of losing them. In this way, the premature birth of the baby, already antecipated during pregnancy, turned real this possibility and made this experience a challenge. However, it was observed that when the initial moments of fear were overcome the belief of being capable of keeping the baby alive emerged.
\end{abstract}

Keywords: motherhood; assisted reproduction; infertility.

$\mathrm{O}$ indivíduo não nasce pai ou mãe, mas torna-se pai ou mãe, por meio de um longo processo de aprendizagem, de transformação e de reflexão acerca de sua descendência, que se estende além do vínculo biológico (Solis-Ponton, 2004).

A parentalidade ${ }^{2}$ pode ser descrita como uma formação mental que se organiza por meio do tecido de representações que se formam desde a infância e evoluem com o desenvolvimento psicológico da criança, e, mais tarde, do adolescente (SolisPonton, 2004). Envolve níveis conscientes e inconscientes do funcionamento mental, constrói-se e se transforma ao longo do ciclo vital (Lebovici, 2004) e pressupõe um trabalho interno dos pais, do qual participam todos os membros da família, desde o recém-nascido até os seus avós (Houzel, 2004; Solis-Ponton, 2004).

Entretanto, nos casos em que a infertilidade em um dos membros do casal, ou em ambos, impede a concepção natural, o casal pode recorrer às técnicas de reprodução medicamente assistida (TRA), tais como a Fertilização in vitro (FIV), a Inseminação Intra-Uterina (IIU), a Injeção Intracitoplasmática de Espermatozóides (ICSI), a Doação de Embriões e a Sessão Temporária de Útero (surrogacy), como uma possibilidade de realização de seu projeto parental (Comitê Internacional para Monitorização da Tecnologia Reprodutiva Assistida \& Organização Mundial da Saúde, 2009).

Com a gravidez e o nascimento de um bebê após o tratamento por TRA, novos sentimentos, vivências e desafios se impõem ao casal durante a transição para a maternidade e a paternidade, cujas implicações ainda são pouco conhecidas (McMahon, Gibson, Leslie, Cohen, \& Tennant, 2003). Apesar de significar a possibilidade de realizar o projeto parental e constituir uma família, a chegada de um bebê nesse contexto também representa uma situação para a qual existe pouca informação na literatura 
(Makuch \& Kahalle, 2009).

Estudos encontrados investigam a transição para a maternidade e a paternidade em casais que conceberam por TRA, em momentos distintos, sendo que neste estudo serão considerados apenas os aspectos relativos à maternidade. Alguns destes estudos abarcam desde a gestação até os primeiros meses de vida do bebê (Cox, Glazebrook, Sheard, Ndukwe, \& Oates, 2006; Repokari et al., 2005; Sydsjö,Wadsby, Kjellberg, \& Sydsjö, 2002; Ulrich, Gagel, Hemmerling, Pastor, \& Kentenich, 2004), enquanto outros, contemplam somente o período pós-nascimento (Greenfeld \& Klock, 2001; Golombok et al., 2007; Hjelmstedt et al., 2004; McMahon, Ungerer, Tennant, \& Saunders, 1997).

Quanto aos principais temas de interesse desses estudos, destacam-se ansiedade (Cox et al., 2006; Greenfeld \& Klock, 2001; Repokari et al., 2005), depressão (Cox et al., 2006; Golombok et al., 2007; Greenfeld \& Klock, 2001), estresse (Golombok et al., 2007; Greenfeld \& Klock, 2001; Hjelmstedt et al., 2004; Repokari et al., 2005), temperamento, comportamento (Sydsjö et al., 2002) e percepção do bebê (Gibson, Ungerer, Tennant, \& Saunders, 2000), ajustamento emocional à maternidade (McMahon et al.,1997), relacionamento conjugal (Sydsjö et al.,2002; Ulrich et al., 2004), competência parental (Cox et al., 2006), saúde mental (Repokari et al., 2005).

Dentre os resultados, o nível de estresse encontrado nos genitores é enfatizado pela maior parte dos estudos, sendo observada redução do estresse parental ao longo do tempo (Greenfeld \& Klock, 2001) e semelhança desses níveis de estresse entre grupos de mães de gêmeos e mães de trigêmeos (Golombok et al., 2007). Além disso, os achados apontaram para maior resiliência para enfrentar eventos estressores (Repokari et al., 2005) e uma visão mais otimista do relacionamento conjugal, da parentalidade e do próprio bebê, o que pode ser uma decorrência da experiência da infertilidade, segundo os autores (Sydsjö et al., 2002). Os desafios encontrados nesse período foram percebidos, pelos casais que utilizaram TRA, como inerentes à parentalidade (Hjelmstedt et al., 2004).

Quanto às medidas de ansiedade, depressão e ajustamento conjugal nos primeiros meses do bebê, os resultados revelaram que não foi encontrada diferença entre os grupos que conceberam naturalmente e os que utilizaram FIV (Greenfeld \& Klock, 2001; McMahon et al.,1997), sugerindo que os dois grupos enfrentam os mesmos tipos de problemas e lidam adequadamente com eles.

Em geral, percebe-se o predomínio de estudos quantitativos, com grandes amostras, avaliadas por meio de instrumentos fechados e padronizados, que detectam aspectos isolados, mas não acessam o tornar-se mãe nesse contexto. Os dados originados a partir desses instrumentos, embora relevantes para identificar questões de pesquisa e intervenção, constituem apenas fragmentos do complexo processo de transição para a maternidade e possibilitam uma compreensão parcial e fragmentada sobre o mesmo. Verifica-se, portanto, uma preocupação em apontar sintomas e dificuldades apresentadas pelos participantes nesse contexto, valendo-se de comparações de resultados obtidos por meio de escalas e inventários, sem, no entanto, buscar a compreensão da experiência de tornar-se pai e mãe.

Considera-se que o complexo processo de tornar-se mãe nesse contexto estende-se para além do que é mensurável. Presença versus ausência, maior intensidade versus menor intensidade, são binômios incapazes de abarcar a totalidade da experiência psíquica vivida pelas mulheres ao longo desse processo, experiência essa que se inicia com dor psíquica e coloca o sujeito frente a frente com a sua história de vida. Além disso, envolve transformações psíquicas profundas, passando pela aceitação de uma nova identidade (de fértil) e estendendo-se até o exercício da maternidade, caminho percorrido com muitos conflitos, desafios e impasses.

Como já foi demonstrado pelas teorizações psicanalíticas que a concepção não é meramente biológica, mas também psíquica (Raphael-Leff, 1997), é preciso compreender com profundidade como se desenrola o processo de tornar-se mãe, pois as interações que se estabelecerão na díade mãe-bebê são essenciais para o desenvolvimento emocional do bebê, bem como para o desenvolvimento das competências dessas mães. Além disso, observa-se que o processo de tornar-se mãe no contexto da reprodução medicamente assistida não tem sido contemplado pelos estudos da área, deixando uma lacuna importante. Dessa forma, este estudo teve como objetivo investigar o processo de tornar-se mãe em mulheres que conceberam por TRA, aos três meses de vida do bebê.

\section{Método}

\section{Participantes}

Participaram deste estudo três mulheres oriundas de um projeto maior, em parceria com o serviço de reprodução medicamente assistida de um hospital público, no Rio Grande do Sul, que concordaram em participar desta pesquisa e assinaram o Termo de Consentimento Livre e Esclarecido. As participantes, que serão chamadas de Luiza, Vitória e Raquel (nomes fictícios), conceberam com o auxílio de TRA e seus bebês se encontravam no terceiro mês de vida. A seguir, a Tabela 1 apresenta os dados sociodemográficos das participantes.

Tabela 1

Características sociodemográficas dos participantes

\begin{tabular}{lcccc}
\hline Participantes & Idade & Escolaridade & Causa infertilidade & Tentativas \\
\hline Vitória & 39 & superior & masculina & 1 \\
Luiza & 40 & superior & feminina & 2 \\
Raquel & 27 & médio & feminina & 2 \\
\hline
\end{tabular}

\section{Procedimentos}

A partir de um levantamento realizado pela equipe do serviço de reprodução medicamente assistida de um hospital público, com o intuito de verificar quais de suas pacientes haviam obtido sucesso no tratamento, foi encaminhada à pesquisadora uma listagem contendo nomes e telefones dessas pacientes para posterior contato. As participantes que concordaram em participar deste estudo ${ }^{3}$ foram contatadas em dois momentos: no terceiro trimestre gestacional (fase 1, com dados anteriores a este estudo) e no terceiro mês de vida do bebê (fase II, contemplada por este estudo). Com aquelas que demonstraram interesse em participar após o nascimento do bebê, foi marcado um encontro em suas casas, no qual foi realizada a Entrevista sobre a Experiência da Maternidade (Núcleo de Infância e Família 
[NUDIF], 1999), composta por blocos de questões que enfocam como a mãe vê o desenvolvimento do bebê, as percepções e sentimentos quanto à maternidade, as mudanças percebidas, a rotina após o nascimento do bebê, o apoio recebido e a ida da criança para a creche.

Os resultados foram discutidos a partir da literatura, tendo como principais eixos interpretativos a Constelação da Maternidade, proposta por Stern (1997), com os temas (1) Vida-Crescimento; (2) Relacionar-se Primário; (3) Matriz de Apoio e (4) Reorganização da Identidade. O tema VidaCrescimento refere-se à capacidade da mãe de manter o bebê vivo e de propiciar o seu crescimento e desenvolvimento físico, contemplando diversos medos, tais como de que o bebê morra ou que não se desenvolva bem. Já o tema Relacionar-se Primário refere-se ao envolvimento social e emocional da mãe com o seu bebê, levando em consideração as dúvidas que surgem nessa fase sobre sua capacidade de amá-lo, sentir-se amada por ele e reconhecê-lo como o seu bebê. O tema seguinte, Matriz de Apoio, refere-se à necessidade da mãe de criar, permitir, aceitar e regular uma rede de apoio protetora e boa, que a ajude a realizar as duas tarefas propostas nos temas anteriores. O último tema, Reorganização da Identidade, relaciona-se à necessidade da mãe de transformar e reorganizar a sua identidade, garantindo assim, que redirecione seus investimentos emocionais, sua distribuição de tempo e energia.

\section{Resultados e Discussão}

Através dos três casos estudados, buscou-se investigar o processo de tornar-se mãe em mulheres que engravidaram por meio de TRA, levando-se em consideração o conteúdo das entrevistas realizadas aos três meses de vida do bebê. Os dados obtidos a partir das entrevistas foram submetidos a uma análise qualitativa de conteúdo (Laville \& Dione, 1999).

A compreensão dos achados baseou-se nos temas propostos pela Constelação da Maternidade (Stern, 1997) por ser este aporte capaz de abarcar a complexidade da experiência psíquica vivida por estas mulheres após o nascimento do bebê, levandose em consideração algumas semelhanças e particularidades na vivência dos temas, exemplificando com verbalizações ilustrativas das próprias mães.

Tema: Vida-Crescimento. Este primeiro tema, cujo ponto fundamental é a preocupação da mãe em manter a sobrevivência de seu bebê e facilitar o seu crescimento e desenvolvimento de forma adequada, apresenta-se neste momento permeado pelo medo de que o bebê não sobreviva, uma vez que todos nasceram com idade gestacional em torno de 36 semanas, sendo considerados "pré-termo" segundo a Red Latino-americana de Reproducción Asistida (www.redlara.com). Para fins deste estudo, os bebês "pré-termo" serão referidos como prematuros.

Alguns aspectos relativos à vivência deste tema foram semelhantes entre as mães deste estudo. Com relação ao parto prematuro, observou-se que este momento pode ter sido vivido como uma possibilidade de concretização da fantasia de não ser capaz de garantir a sobrevivência do filho, uma ameaça iminente de perda do bebê, presente desde a gestação. Para Vitória e Raquel, foram momentos assustadores e angustiantes, vindo a mobilizar intensos sentimentos de medo, desamparo e ruptura brusca com o bebê, conforme ilustram seus depoimentos:

só que eu fiquei muito angustiada ... Eu disse: Ah, não é a hora dela doutora (...) Eu não quero que ela nasça agora (...). (Vitória)

Não foi como eu imaginava... foi uma coisa totalmente assim, inesperada (...) eu tive que tirar ele às pressas. (Raquel)

Nesse sentido, o parto prematuro está permeado pela urgência e constitui-se um trauma tanto para a mãe, quanto para o bebê (Gomes, 2004), sendo que a mãe de um prematuro inevitavelmente vive um tumulto emocional decorrente da gravidez interrompida, sentindo-se culpada por ter abandonado seu bebê aos profissionais e ao aparato tecnológico, além de apresentar um sentimento irracional de rejeição e fracasso por ter sido incapaz de manter o bebê em seu ventre (Raphael-Leff, 1997). Dessa forma, a situação de prematuridade provoca uma ruptura abrupta e repentina da simbiose entre a mãe e seu bebê, já que ambos estão incompletos devido à separação precoce (Wirth, 2000), desencadeando sentimentos de perda (Gomes, 2004).

Diferentemente de Vitória e Raquel, apesar dos riscos implícitos da gravidez gemelar, o momento do parto foi vivido por Luiza de forma tranquila em decorrência de ter assistido a inúmeros documentários sobre o tema e ter se sentido acolhida pela equipe naquele momento, conforme aponta:

uma coisa bacana assim. Bem tranquila, né? O momento em si. (...) tinha um anestesista... participando, que eu adorei o estilo dele, né? Ele ficou sentado aqui atrás de mim e me dizia a hora. Agora vai ser feito tal e tal coisa. Oh agora saiu um bebê, agora saiu outro bebê...'. Então ele foi me explicando e aquilo me tranquilizou muito, né? (Luiza)

A necessidade de internação em UTI Neonatal e a consequente separação da mãe e do bebê por período prolongado, em função de intercorrências, como infecção contraída e baixo peso, foram consideradas fator agravante do medo de perder o bebê e o sentimento de incapacidade de garantir a sua sobrevivência verificado de forma semelhante em Vitória e Luiza, sendo que o bebê de Raquel não necessitou de internação em UTI Neonatal. Conforme Gomes (2004), nesse contexto de prematuridade e internação, os contatos da mãe com o seu bebê são permeados pelo medo da morte em decorrência da gravidade do estado do bebê e do fato da mãe não conseguir se colocar como fonte de vida para seu filho, sendo toda situação envolvida por uma alta tecnicidade e precisão, conforme ilustram os relatos:

com aquele estresse, medo de perder minha filha ...ou de sequelar, aquela coisa toda...(...) Então eles tiravam de dentro da estufa, com aquele monte de fios que tava ligado neles e eu botava aqui no corpo e fechava o...uniforme (...). (Vitória)

e eu com ela na UTI, eu tinha que ser forte...(...) foi um período bem difícil assim pra gente. (Luiza)

A vinda para casa com os bebês foi vivida por Vitória com angústia e estresse, pois a filha apresentou dificuldade para mamar no peito, cólicas e refluxo, chorando a maior parte do tempo: "bastante coisa para dar conta". Já Luiza, necessitou se 
adaptar a uma rotina doméstica especial em função dos gêmeos, sentindo sua privacidade invadida e, talvez, o exercício da maternidade ameaçado, tanto pela doença de um dos bebês, como pelo fato de ter outras pessoas ajudando a cuidá-los. Além disso, cada um deles apresentou uma peculiaridade que a preocupou: “(...) uma intercorrência pela Renata, que tá com refluxo e alergia a leite (...) momentos de muita dor; foi uma situação muito estressante (...), mas foi um susto terrível [doença do Lucas]".

Dados da realidade externa, tais como as doenças e a rotina criada provocaram momentos de estresse intensos, já que Luiza estava constantemente em estado de alerta, mostrando-se disponível, embora exausta e com sinais de depressão, conforme aponta: “...eu notei que depois que eu vim pra casa com os bebês, que eu tava muito irritada (...) tudo me irritava. Eu tava numa situação bem complicada...”.

Apesar de não ter enfrentado o contexto estressante de uma UTI Neonatal como as demais mães, indo para casa com seu bebê nos primeiros dias após seu nascimento, deparar-se com um bebê prematuro e supostamente frágil e vulnerável, fez Raquel sentir-se solitária, insegura e estressada, conforme relatou: "Mas em casa também foi difícil. Todo mundo, os que podiam ajudar trabalhavam, daí tinha que ficar junto comigo [o bebê], daí eu não podia me mexer [cesárea]".

daí, tudo que eu fazia tava errado [referindo-se aos comentários de sua mãe]. Eu chorei bastante nos primeiros dias, chorei bastante... acho que foi uma semana assim, chorando. (...) só que a gente pensa, com os outros é tão fácil [cuidados com os sobrinhos]. (Raquel)

Em relação às particularidades desse momento, Mittaag e Wall (2004) destacam que a chegada em casa é, ao mesmo tempo, muito esperada e muito temida, pois, a partir dela, os genitores tornam-se responsáveis pelos cuidados com o seu bebê. Percebe-se que para as mães deste estudo, chegar em casa com um bebê prematuro, ou com dois, significou deparar-se com a fragilidade inerente à condição de prematuro e com a sua própria prematuridade enquanto mãe, momento em que medos e fantasias foram exacerbados.

Entende-se, portanto, que o tema Vida-Crescimento foi intensamente afetado pela prematuridade e a consequente internação dos bebês em UTI Neonatal, uma vez que o nascimento antes do tempo previsto e a necessidade de cuidados de um terceiro, a UTI, corroboraram as fantasias dessas mães de serem incapazes de garantir a sobrevivência de seu bebê intra-útero. Além disso, e o entorno que se faz necessário para mantê-lo vivo, impediram que as mães desempenhassem as tarefas iniciais nos cuidados de seus bebês, o que talvez possa ter sido a confirmação de seu temor de não ser suficientemente boa para o bebê. Ressalta-se que o impacto desta experiência foi intenso, vindo a ocupar grande parte da entrevista realizada com as mães aos três meses de vida do bebê.

Tema: Relacionar-se primário. O tema Relacionar-se Primário (Stern, 1997), que contempla o estado descrito por Winnicott (1958/2000) como preocupação materna primária, constitui-se num estado de sensibilidade exacerbada, quase uma doença, durante o qual a mãe adapta-se de maneira sensível e delicada às necessidades do bebê.
No contexto da prematuridade do bebê, e também de suas mães, no que diz respeito a assumir os cuidados e responsabilidades inerentes ao status de mãe, Brazelton e Cramer (1992) consideram que uma imaturidade de duas semanas pode desencadear diferenças comportamentais, que tendem a influenciar as reações dos pais ao seu bebê, caso não sejam instruídos sobre algumas questões acerca da condição dos bebês. Em relação aos cuidados maternos, Szejer (1999) refere que diante do parto pré-termo, a mãe vê toda a sua dedicação cair no vazio, uma vez que não se sente capaz de propiciar ao seu bebê os cuidados necessários à sua sobrevivência.

Em relação a esse tema, convém ressaltar que a permanência dos bebês de Vitória e Luiza na UTI Neonatal por, aproximadamente, 30 dias, as mantinha em constante estado de alerta, o que pode ter influenciado a relação que se estabeleceu entre elas e seus bebês, verificado nas verbalizações a seguir:

E eu cheguei a um ponto que eu não aguentava mais ouvir ela chorar. Era uma coisa difícil assim. (...) eu tava estressada também...não tava aguentando (...) houve muito estresse no início. (Vitória)

No início assim foi um pouquinho estressante... Assim, logo que ela veio prá casa foi um período bem difícil prá gente (...) eu não conseguia dormir (...) daí eu não conseguia acordar (...) ... na primeira noite tu não consegue dormir. (Luiza)

No entanto, essas dificuldades encontradas no manejo das mães com seus bebês no período imediato à chegada em casa, foram aos poucos cedendo lugar à crença na capacidade de cuidálos e de se adaptar às novas exigências dessa fase, conforme ilustram as falas abaixo:

Então agora [aos três meses] é um outro momento...um momento melhor. Eu diria que agora, nesse período a gente se adaptou um pouco mais. No início foi mais difícil porque é uma rotina nova na casa. (...) Eu me sentia exausta o tempo todo (...) Muito irritada...não com os bebês, mas com as pessoas que estavam em volta (...) A casa cheia de gente o tempo todo.(...) Tu não tem mais privacidade como era antes. (Luiza)

Mas agora passou essa fase. Agora eu acho que ela tá na melhor fase. (Vitória)

No início, o primeiro mês foi complicado (...) aí depois de um mês ele ficou mais calmo (...) ali começou a engrenar a situação toda (...). (Raquel)

Em relação à Raquel, pode-se supor que o fato de não ter observado e aprendido a manejar com um bebê prematuro e vulnerável, como as demais participantes cujos bebês permaneceram na UTI, talvez tenha influenciado a sua vivência dos primeiros períodos com seu bebê, já que ela própria sugeriu sentir-se também "prematura" para cuidar de seu filho, conforme ilustra a sua fala: "no início eu até achei que eu não ia ficar apavorada (...) mas quando eu fazia [cuidados com o bebê], me sentia apavorada... que daí eu tinha medo [que o bebê vomitasse, engasgasse]".

Entretanto, mesmo as mães que passaram pelo período de 
adaptação aos seus bebês prematuros ao longo da internação demonstraram insegurança e medo de errar nos cuidados com os bebês, sendo esse um aspecto comum entre as três mães participantes, conforme pode ser observado em seus relatos:

porque eu não estou ainda suficientemente segura... porque eu não consegui impor o meu ritmo. (Vitória)

Eu não via o que tavam fazendo com os bebês (...) Eu tinha muita dificuldade de confiar no pessoal... Fiquei muito desconfiada. (Luiza)

agora já estou me adaptando mais, antes eu...ficava sempre em cima dele (...). (Raquel)

Esse momento pode ser compreendido segundo Winnicott (1958/2000), que aponta que, no início, a díade se conhece pouco e ainda não há, entre a mãe e seu bebê, um padrão de comunicação que facilite à mãe identificar as necessidades do bebê. A relação entre eles, portanto, é não verbal e intensamente emocional.

Dados da realidade objetiva, como as doenças e a possível fragilidade dos bebês, acabaram por intensificar nessas participantes esse sentimento de incapacidade de manter a sobrevivência e o desenvolvimento de seu bebê, provocando sentimentos de raiva, culpa, depressão e estresse. Com o passar do tempo, a confiança em si mesmas foi lentamente instaurandose, pois, apesar das intercorrências iniciais, os bebês estavam vivos e desenvolvendo-se adequadamente. Os primeiros meses, embora angustiantes, foram também uma oportunidade de provarem para si mesmas que eram capazes de cuidar de seus bebês adequadamente e que tinham coisas boas dentro de si.

Entende-se, portanto, que o modo como as mães deste estudo relacionaram-se com seus bebês nesses três meses foi inicialmente permeado pelo impacto causado pela prematuridade, acarretando temor de que esses bebês não sobrevivessem em decorrência de sua imaturidade orgânica e vulnerabilidade a algumas doenças.

Tema: Matriz de Apoio. O terceiro tema contempla a rede de apoio capaz de proteger a mãe e garantir que possa dedicar-se ao seu bebê. Nesse período, a mãe necessita sentir-se cercada, apoiada, acompanhada, valorizada, apreciada, instruída e ajudada, de acordo com suas necessidades, sendo que a ausência dessa forma de apoio compromete a função materna (Stern, 1997).

Cada participante deste estudo se organizou de forma diversa para contar com o apoio familiar ou profissional, a fim de que aos bebês fossem assegurados os cuidados necessários naquele momento. Enquanto o marido convalescia de uma cirurgia, Vitória contou com a ajuda da mãe na maior parte do tempo: "Eu tinha, não o apoio físico [do marido]... às vezes ele não podia pegar ela porque fez uma cirurgia... mas o apoio moral eu tinha... psicológico (...). Minha mãe também ficou aqui comigo". Raquel teve o apoio do marido, da mãe e de irmãs, embora considere que a mãe "se atrapalhasse um pouco (...) me deixasse nervosa" e a "criticasse". Já a situação de Luiza, com gêmeos prematuros e com algumas complicações, exigiu a busca por auxílio profissional, conforme assinalou: “A gente tem... a de dia [babá], tem de noite". Esporadicamente, contava também com o apoio de uma tia e do marido, que necessitava trabalhar para garantir financeiramente a permanência da estrutura preparada para os cuidados com os bebês.

Destaca-se, nesse tema, a insegurança demonstrada por Luiza e Vitória ao necessitar ajuda de outras pessoas nos cuidados com os bebês, mesmo que temporariamente, comentando que

eu tinha muita dificuldade de confiar no pessoal que trabalhava à noite...talvez, pelo fato que eu tinha que me retirar. (Luiza)

Tem uma pessoa que ajuda aqui em casa, mas eu não deixo com ela. Assim, no máximo, se eu vou tomar um banho ela fica reparando [o bebê]. (Vitória)

Pode-se supor que essa insegurança seja decorrente da prematuridade dos bebês e dos riscos de perdê-los, vivenciados no período da internação. Além disso, há também a prematuridade dessas mães, isto é, o nascimento dos filhos foi antecipado, ocorreu numa situação emergencial e de risco. Esta condição, como referido anteriormente, talvez tenha reforçado nessas mães sentimentos presentes desde a gestação.

Em função da prematuridade, as visitas aos bebês de Luiza foram proibidas pelo médico. A ausência de familiares e amigos, uma rede de apoio importante nesse momento, foi vivida por ela como isolamento, pois seu "envolvimento era apenas com os bebês", necessitando outros contatos e trocas afetivas, o que é ilustrado em sua fala:

Pela prematuridade dos bebês, o pediatra proibiu visitação, até completarem em torno de dois meses, então a gente não teve assim essa oportunidade imediata, que nem a maioria dos casais tem, de um retorno social, né? Das pessoas virem, visitarem... aquela coisa que é boa também, que faz parte, né?... eu fiquei muito ilhada. (Luiza)

Percebe-se que o tema Matriz de Apoio apresentou como características a insegurança frente à possibilidade de os bebês serem cuidados por outras pessoas, talvez vivido pelas três participantes como uma ameaça à sua condição de mãe, tão difícil de ser conquistada. Cabe questionar quais temores e fantasias habitavam o interior dessas mães: não ser uma mãe "suficientemente boa", vindo a ser substituída; não ser suficientemente encantadora para esses bebês, a ponto de ser trocada; ou que esses bebês não fossem bem cuidados, vindo a morrer.

Aos três meses do bebê, a questão de colocá-los na creche quando retornassem às suas atividades, ainda era assunto polêmico para as mães. Embora Luiza planejasse levar os gêmeos para uma creche quando completassem oito meses, temia pelos riscos de doenças que pudessem ser contraídas no convívio com outros bebês, demonstrando, ainda, perceber os filhos como frágeis, talvez uma cicatriz deixada pela experiência da reprodução medicamente assistida e pela prematuridade dos bebês. Entretanto, Vitória pensava em levar a filha para a creche apenas meio turno, pois, no outro, ficaria em casa com ela, enquanto Raquel talvez deixasse o filho em uma creche, embora acreditasse que a adaptação do filho seria muito difícil para ela. O receio de afastar-se dos filhos, observado nas três 
participantes, talvez tenha se intensificado em decorrência do parto prematuro, vivido como abrupto, bem como das primeiras experiências com um bebê prematuro e vulnerável.

Tema: Reorganização da Identidade. O quarto tema proposto por Stern (1997) aborda a necessidade da mãe de transformar e reorganizar a sua identidade, passando de filha para mãe, de esposa para mãe do filho do casal e de profissional para mãe de família.

$\mathrm{O}$ contexto em que essas mudanças de identidade e de status aconteceram neste estudo foi permeado, também, pelo impacto da prematuridade, influenciando a reorganização da identidade de filha para identidade de mãe. Vitória, Luiza e Raquel viveram essa mudança de status mantendo-se em estado de alerta, certificando-se sempre que os bebês estavam bem, conforme aponta uma das mães: "Então a gente não sabia se ia respirar, se estava tudo bem [quando o bebê saísse da UTI Neonatal]". (Vitória)

Este fato chamou a atenção neste estudo, uma vez que o medo de não conseguir garantir a sobrevivência do feto, conforme verificado durante a gestação, na Fase I deste estudo, e depois a sobrevivência do bebê e, assim, inviabilizar a maternidade, foi uma constante desde o tratamento.

Tais achados encontram respaldo em McMahon (1999), quando afirma que a reprodução medicamente assistida pode afetar a aquisição da identidade materna em mulheres com histórico de infertilidade, sendo que essas mulheres frequentemente necessitam confirmar essa identidade, assegurar sua condição de mãe, numa tentativa de reorganizar-se face ao período de turbulência pelo qual passaram, o que pode ser verificado em seus depoimentos:

O que importa é o quanto eu de fato me sinto mãe (...). Eu sou mãe e não tem pra ninguém [referindo-se ao fato de sentir-se mãe no contexto da doação de gametas](...). Tinha uma coisa do que que é mesmo o teu papel, qual é o meu, que que é que tu tem que fazer e o que que eu tenho que fazer (...). E daí, aos poucos, eu fui me autorizando a fazer e depois melhorei (...) eu acordo às 7 horas e faço as minhas coisas. (...) não é fácil... é muita mudança na vida. (Luiza)

O pior momento é quando a gente sai para jantar fora, pois se a gente sentar para comer alguma coisa, ela vai chorar (...) daí recolhe e leva para casa. (...) estava dirigindo dentro de oito dias (...) não tinha quem me levasse, né? (Vitória)

\section{Considerações finais}

Os avanços tecnológicos ocorridos na área da medicina reprodutiva propiciaram aos casais inférteis a possibilidade de realizar o projeto parental. Entretanto, o desgaste físico e emocional, as frustrações enfrentadas na tentativa de concretização desse projeto, conferem à maternidade um caráter específico, com repercussões ainda pouco conhecidas. A experiência traumática desse período é, por vezes, intensificada pelo frequente nascimento prematuro dos bebês, que impõe às mães uma nova realidade, na qual os cuidados com o bebê prematuro ficam ao encargo de uma UTI Neonatal, uma espécie de útero substituto.

Examinando o processo de tornar-se mãe nas participantes deste estudo, sob a perspectiva da Constelação da Maternidade (Stern, 1997), observa-se que o impacto causado pela prematuridade, com o consequente medo de perder o bebê e o sentimento de não ter/gerar "coisas boas" dentro de si, permeou a experiência dessas mães em cada um dos quatro temas da Constelação. Descrença na sua capacidade de produzir "coisas boas", com sentimento de ser incapaz de garantir a sobrevivência do bebê, marcaram a vivência desse momento, talvez como cicatrizes deixadas pelo difícil período de tratamento da infertilidade. É possível pensar também, que a experiência da infertilidade possa ter afetado a crença dessas mães na sua capacidade de gerar e manter vivo um bebê e que a vivência das primeiras experiências com um bebê prematuro tenha provocado uma demanda psíquica imensa nessas mães.

Portanto, a prematuridade e a permanência desses bebês na UTI Neonatal, podem ter corroborado medos e reforçado sentimentos e expectativas de incapacidade relacionados ao contexto da reprodução medicamente assistida, intensamente vividos e anunciados desde a gestação. Frente a essa situação de ruptura brusca, mães e bebês necessitaram de um tempo para se reorganizar, absorver o impacto causado e assegurar a sua condição de mãe, abalada nesse momento. Além disso, observouse que o tema Vida-Crescimento ocupou um espaço significativo na fala das participantes e teve como questão primordial a ameaça de concretização da fantasia de perder o bebê, já presente no imaginário desses participantes desde a gestação.

Os resultados do presente estudo sugerem que a vivência da maternidade no contexto da reprodução medicamente assistida apresenta particularidades, tornando-se um desafio para as mães. Assim, a investigação desta temática é de extrema importância, uma vez que por si só a maternidade constitui-se num evento complexo, sendo que inserida no contexto das TRA, com frequentes nascimentos prematuros, sentimentos e vivências são intensificados.

Tomando os achados do presente estudo, recomenda-se que futuras pesquisas abordem temas relativos ao contexto da reprodução medicamente assistida, tais como consequências emocionais do tratamento com sucesso ou tentativas fracassadas, vivência da gestação única ou gemelar, vínculo pais-bebê, dentre outros, a fim de que possam ser planejadas estratégias de prevenção e intervenção, priorizando as dificuldades encontradas na transição para a maternidade.

\section{Referências}

Brazelton, T. B., \& Cramer, B. G. (1992). As primeiras relações (M. B. Cipolla, Trad.). São Paulo: Martins Fontes.

Comitê Internacional para Monitorização da Tecnologia Reprodutiva Assistida, \& Organização Mundial da Saúde. (2009). Glossário revisado da Terminologia das Técnicas de Reprodução Assistida (TRA). (Red Latinoamericana de Reproducción Asistida, Trad.). Recuperado de http://www.redlara.com

Cox, S. J., Glazebrook, C., Sheard, C., Ndukwe, G., \& Oates, M. (2006). Maternal self-esteem after succesful treatment for infertility. Fertility and Sterility, $85(1), 84-89$

Gibson, F., Ungerer, J., Tennant, C., \& Saunders, D. (2000). Parental adjustment 
and attitudes to parenting after in vitro fertilization. Fertility and Sterility, 73(3), 565-574.

Golombok, S., Olivennes, F., Ramogida, C., Rust, J., Freeman, T., \& The Follow-up team (2007). Parenting and the psychological development of a representative sample of triplets conceived by assisted reproduction. Human Reproduction, 22(11), 2896-2902.

Gomes, A. L. H. (2004). A relação mãe-bebê na situação de prematuridade extrema: possibilidades de intervenção da equipe multiprofissional. Psicologia Hospitalar, 2(2). Recuperado de http://pepsic.bvsalud.org/scielo. php?pid=S1677-74092004000200004\&script=sci_arttext

Greenfeld, D., \& Klock, S. (2001). Transition to parenthood among in vitro fertilization patients at 2 and 9 months postpartum. Fertility Sterility, 73(3), 626-627.

Hjelmstedt, A, Widström, A. M., Wramsby, H., \& Collins, A. (2004). Emotional adaptation following successful in vitro fertilization. Fertility and Sterility, 81(5), 1254-1264.

Houzel, D. (2004). As implicações da parentalidade. In M. C. P. Silva, \& L. Solis-Ponton (Orgs.), Ser pai, ser mãe. Parentalidade: um desafio para o terceiro milênio (pp. 47-51). São Paulo: Casa do Psicólogo.

Laville, C., \& Dione, J. (1999). A construção do saber: manual de metodologia em ciências humanas. Porto Alegre: Artmed.

Lebovici, S. (2004). Diálogo Letícia Solis-Ponton e Serge Lebovici. In M. C. P. Silva, \& L. Solis-Ponton (Orgs.), Ser pai, ser mãe. Parentalidade: um desafio para o terceiro milênio (pp. 21-27). São Paulo: Casa do Psicólogo.

Makuch, M. Y., \& Kahalle, E. P. (2009). Estudos em Psicologia e Reprodução Humana Assistida (RHA). In R. M. Melamed, L. Seger, \& E. Borges Jr. (Orgs.), Psicologia e Reprodução Humana Assistida - uma abordagem multidisciplinar (pp.143-164). São Paulo, Brasil: Editora Santos.

McMahon, C. A., Ungerer, J. A., Tennant, C., \& Saunders, D. (1997). Psychosocial adjustment and the quality of the mother-child relationship at four-months postpartum after conception by in vitro fertilization. Fertility and Sterility, 68(3), 492-500.

McMahon, C. A. (1999). Does assisted reproduction make an impact on the identity ans self-esteem of infertile women during the transition to parenthood? Journal of Assisted Reproduction and Genetics, 16(2), 59-62.
McMahon, C., Gibson, F., Leslie, G., Cohen, J., \& Tennant, C. (2003). Parents of 5 -year-old in vitro fertilization children: psychological adjustment, parenting stress, and the influence of subsequent in vitro fertilization treatment. Journal of Family Psychology, 17, 361-369.

Mittaag, B. F., \& Wall, M. L. (2004). Pais com filhos internados na UTI Neonatal sentimentos e percepções. Família, Saúde e Desenvolvimento, 6(2), 134-145.

Núcleo de Infância e Família - NUDIF. (1999). Entrevista sobre a Experiência da Maternidade. Instrumento não publicado. Porto Alegre: Universidade Federal do Rio Grande do Sul.

Raphael-Leff, J. (1997). Gravidez: a história interior. Porto Alegre: Artes Médicas.

Repokari, L., Punamäki, P., Poikkeus, S., Vilska, S., Unkila-Kallio, L., Sinkkonen, ... Tulppala, M. (2005). The impact of successful assisted reproduction treatment on female and male mental health during transition to parenthood: a prospective controlled study. Human Reproduction, 20(11), 3238-3247.

Solis-Ponton, L. (2004). A construção da parentalidade. In M. C. P. Silva \& L. Solis-Ponton (Orgs.), Ser pai, ser mãe. Parentalidade: um desafio para o terceiro milênio (pp. 29-40). São Paulo: Casa do Psicólogo.

Stern, D. N. (1997). A constelação da maternidade: o panorama da psicoterapia pais/bebê (M. A. V. Veronese, Trad.). Porto Alegre: Artes Médicas.

Sydsjö, G, Wadsby, M., Kjellberg, S., \& Sydsjo, A. (2002). Relationships and parenthood in couples after assisted reproduction and in spontaneous primiparous couples: a prospective long-term follow-up study. Human Reproduction, 17(12), 3342-3250.

Szejer, M. (1999). Palavras para nascer: a escuta psicanalítica na maternidade. São Paulo: Casa do Psicólogo.

Ulrich, D., Gagel, D. E., Hemmerling, A, Pastor V.-S., \& Kentenich, H. (2004). Couples becoming parents: something special after IVF? Journal of Psychosomatic Obstetrics \& Gynecology, 25(2), 99-113.

Winnicott, D. W. (2000). Da pediatria à psicanálise - obras escolhidas (D. Borgomoletz, Trad.). Rio de Janeiro: Imago. (Publicado originalmente em 1958)

Wirth, A. F. (2000). Aplicação do método de observação de bebês em uma UTI neonatal. In N. A. Caron (Org.), A relação pais-bebê: da observação à clínica (pp. 207-232). São Paulo: Casa do Psicólogo.

1. Este trabalho é baseado na tese de doutorado da primeira autora, desenvolvida no Programa de Pós-graduação em Psicologia da Universidade Federal do Rio Grande do Sul, e supervisionada pela segunda.

2. O termo parentalidade será utilizado apenas quando for referido pelos autores citados neste estudo.

3. Participaram deste estudo mães oriundas de um estudo maior intitulado "Transição para a parentalidade e relacionamento conjugal no contexto da reprodução assistida: da gestação ao primeiro ano de vida do bebê”, desenvolvido pelo Núcleo de Infância e Família (NUDIF), da Universidade Federal do Rio Grande do Sul.

Lia Mara Netto Dornelles, doutora em Psicologia pela Universidade Federal do Rio Grande do Sul, é professora da Faculdade de Psicologia da Universidade de Caxias do Sul Pesquisadora do NUDIF/GIDEP/UFRGS. Endereço para correspondência: Rua Anita Garibaldi, 1786 apto. 711, Boa Vista, Porto Alegre-RS. CEP: 90480-200. Tel.: (51)9115-7297. E-mail: liadornelles@terra.com.br Rita de Cássia Sobreira Lopes, doutora em Psicologia pela Universidade de Londres, é professora do Programa de Pós-graduação em Psicologia da Universidade Federal do Rio Grande do Sul. E-mail: sobreiralopes@ portoweb.com.br 